\title{
Midterm results of less invasive approach to ascending aorta and aortic root surgery
}

\author{
Jakub Staromłyńskii ${ }^{1 \#}$, Mariusz Kowalewski ${ }^{1,2,3 \#}$, Wojciech Sarnowski ${ }^{1}$, Radosław Smoczyński ${ }^{1}$, \\ Anna Witkowska ${ }^{1}$, Maciej Bartczak ${ }^{1}$, Dominik Drobiński ${ }^{1}$, Waldemar Wierzba ${ }^{4}$, Piotr Suwalski ${ }^{1}$ \\ ${ }^{1}$ Department of Cardiac Surgery, Central Clinical Hospital of the Ministry of Interior and Administration, Centre of Postgraduate Medical \\ Education, Warsaw, Poland; ${ }^{2}$ Thoracic Research Centre, Collegium Medicum, Nicolaus Copernicus University, Innovative Medical Forum, \\ Bydgoszcz, Poland; ${ }^{3}$ Cardio-Thoracic Surgery Department, Heart and Vascular Centre, Maastricht University Medical Centre, Maastricht, The \\ Netherlands; ${ }^{4}$ Satellite Campus in Warsaw, University of Humanities and Economics in Łódź, Warsaw, Poland \\ Contributions: (I) Conception and design: M Kowalewski, J Staromłyński, P Suwalski; (II) Administrative support: W Wierzba, P Suwalski; (III) \\ Provision of study materials or patients: J Staromłyński, W Sarnowski, P Suwalski; (IV) Collection and assembly of data: J Staromłyński; (V) Data \\ analysis and interpretation: M Kowalewski; (VI) Manuscript writing: All authors; (VII) Final approval of manuscript: All authors. \\ \#These authors contributed equally to this work. \\ Correspondence to: Mariusz Kowalewski, MD. Department of Cardiac Surgery, Central Clinical Hospital of the Ministry of Interior and \\ Administration, Centre of Postgraduate Medical Education, Warsaw, Poland. Email: kowalewskimariusz@gazeta.pl.
}

Background: Minimally invasive aortic valve (AV) surgery has become widely accepted alternative to standard sternotomy. Despite possible reduction in morbidity, this approach is not routinely performed for aortic surgery. Current report aimed to demonstrate early and mid-term outcomes in patients undergoing minimally invasive aortic root- and ascending aorta-replacement with or without concomitant AV replacement (AVR).

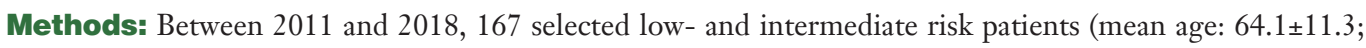
$70 \%$ men; EuroSCORE II 2.58 \pm 3.26 ) underwent minimally invasive aortic surgery. The "V" shaped partial upper sternotomy was performed through a 6-cm skin incision. Patients were divided into minimally invasive root reimplantation/replacement/remodelling (root RRR), supracoronary aorta replacements (SCAR) and SCAR+AVR. Kaplan-Meier estimates of survival were used.

Results: Mean follow-up was 3.1 year (max 7.7 years). Of 167 patients, 82 (49\%) underwent SCAR; 44 (26\%) SCAR + AVR. Forty-one patients (25\%) underwent minimally invasive root RRR. Average aortic diameter was $6.00 \pm 0.46 \mathrm{~cm}$. The cardiopulmonary bypass and aortic cross-clamp time were $152.0 \pm 46.8$ and 101.8 \pm 36.8 minutes. There was one conversion to sternotomy. Median intensive care unit stay was 2.0 (IQR: 1.0-3.0) days. Thirty-day mortality was $1 \%$. Within investigated follow-up, there was one late reoperation due to aortic valve thrombosis; late survival was estimated at $95 \%$ without differences between types of surgery: hazard ratio, $0.81 ; 95 \%$ CI: $0.36-1.81 ; \mathrm{P}=0.61$.

Conclusions: Minimally invasive aortic surgery performed through " $\mathrm{V}$ " shaped partial upper sternotomy is feasible and safe in selected patients regardless of the extent of repair, from supracoronary aorta replacements to complex root surgery.

Keywords: Minimally invasive surgery; aortic root; mini-sternotomy; extracorporeal circulation; valvular disease

Submitted Jun 10, 2020. Accepted for publication Sep 30, 2020.

doi: $10.21037 /$ jtd-20-2165

View this article at: http://dx.doi.org/10.21037/jtd-20-2165 


\section{Introduction}

An important objective in modern cardiovascular surgery is reducing surgical trauma to achieve faster recovery. The benefits of minimally invasive cardiovascular surgery are evident $(1,2)$ with more and more surgeons comfortable with minimally invasive aortic valve replacement (AVR) performed via upper hemi-sternotomy or right minithoracotomy. Assumedly, natural course would be a growing interest in performing aortic surgery via a minimal access incision as well; yet this approach is not routinely employed for aortic disease since these are complex procedures that due to limited exposure demand a high level of surgical skill. Several reports however (3-6) showed that in experienced centres, minimally invasive techniques for patients with ascending aortic aneurysm and aortic valve disease offered similar or better results as compared to conventional sternotomy, with lower perioperative blood transfusion, low valve-related complications, low reoperations rate and shorter length of hospital stay.

Objective of the current study was to report our experience with minimally invasive approach for aortic surgery with or without concomitant aortic valve procedures. We present the following article in accordance with the STROBE reporting checklist (available at http:// dx.doi.org/10.21037/jtd-20-2165).

\section{Methods}

This study conformed to the provisions of the Declaration of Helsinki (as revised in 2013) and was approved by the local ethics committee (CSK MSWiA/KE/215/2018), and each patient signed an informed consent for treatment and use of personal data. Between 2011-2018, 498 patients underwent aortic surgery at our institution. Of those, 167 consecutive elective patients $(33.5 \%)$ were treated with a minimally invasive approach via an upper partial sternotomy. Operative risk was evaluated according to European System for Cardiac Operative Risk Evaluation II (EuroSCORE II) (7). Exclusion criteria for the minimally invasive approach were the following: active aortic valve endocarditis, redo surgery, acute type A dissection, and concomitant cardiac procedures expanding beyond coronary artery bypass to the proximal right coronary artery. No age restrictions were imposed either. In the early experience (2011-2013) aortic dilatation $>60 \mathrm{~mm}$ was an exclusion criterion; that was later lifted with the progression on the learning curve and patients presenting with aortic aneurysms $\leq 70 \mathrm{~mm}$ were included in the study as well. Each patient underwent preoperative angio-computed tomography and echocardiographical exam to determine exact aortic position and dimensions (Figure 1). Presence of extensive aorta calcifications was not an exclusion criterion provided the plaques were not located at cannulation site; coronary angiography was performed in patients $>40$ y.o.; the decision of to the surgical approach ("V" shaped partial upper sternotomy to 3rd or 4th intercostal space (Figures 2,3) was met; yet any deviations from planned procedure were left at the discretion of the involved surgeon.

\section{Surgical technique}

General anesthesia was performed according to the standard protocol. External defibrillator pads were placed and a $3 \mathrm{D}$ transesophageal echocardiography (TEE) probe was positioned in every patient. Each patient had INVOS ${ }^{\circledR}$ cerebral oxygenation monitoring probes (Somanetics Corporation, Troy, MI) placed as well.

The ascending aorta and aortic root were exposed by or " $V$ " shaped partial upper sternotomy beginning at sternal notch and extending to 3 rd or $4^{\text {th }}$ intercostal space (Figures 2,3A,B); after identification and mobilization of innominate vein, pericardium was opened and 7-8 pericardial stay sutures placed (Figure 3C). After systemic heparinization, direct aortic and right atrium appendage cannulation was performed; (EOPA arterial cannula; Medtronic, Inc, Minneapolis, MN USA) was positioned in the proximal portion of aortic arch. For the venous drainage, a three-stage MC2X cannula (Medtronic, Inc) was placed in the right atrium-inferior vena cava and later pulled through the $1.5 \mathrm{~cm}$ sub-xiphoid incision with right atrium pushed down (Figure 3D). Cardiopulmonary bypass was commenced. Cell saver use was left to the decision of operating surgeon. Depending on surgeons' preference the patient was cooled down to $32-34{ }^{\circ} \mathrm{C}$. Left vent was placed into the left atrium via the upper right pulmonary vein.

Aorta was than cross-clamped and opened; cold blood cardioplegia was delivered selectively through both coronary ostia and repeated every 20-25 minutes; while no such case occurred, retrograde delivery of cardioplegia is also possible with this approach. Surgical technique for aneurysm excision, valve replacement and aortic anastomoses did not differ from standard sternotomy approach (Figure 4). After Dacron grafts were in place, it was again left to the surgeons' discretion to use fibrin or Bioglue (CryoLife, Kennesaw, GE, USA) to support the hemostasis in the aortic anastomoses site. 

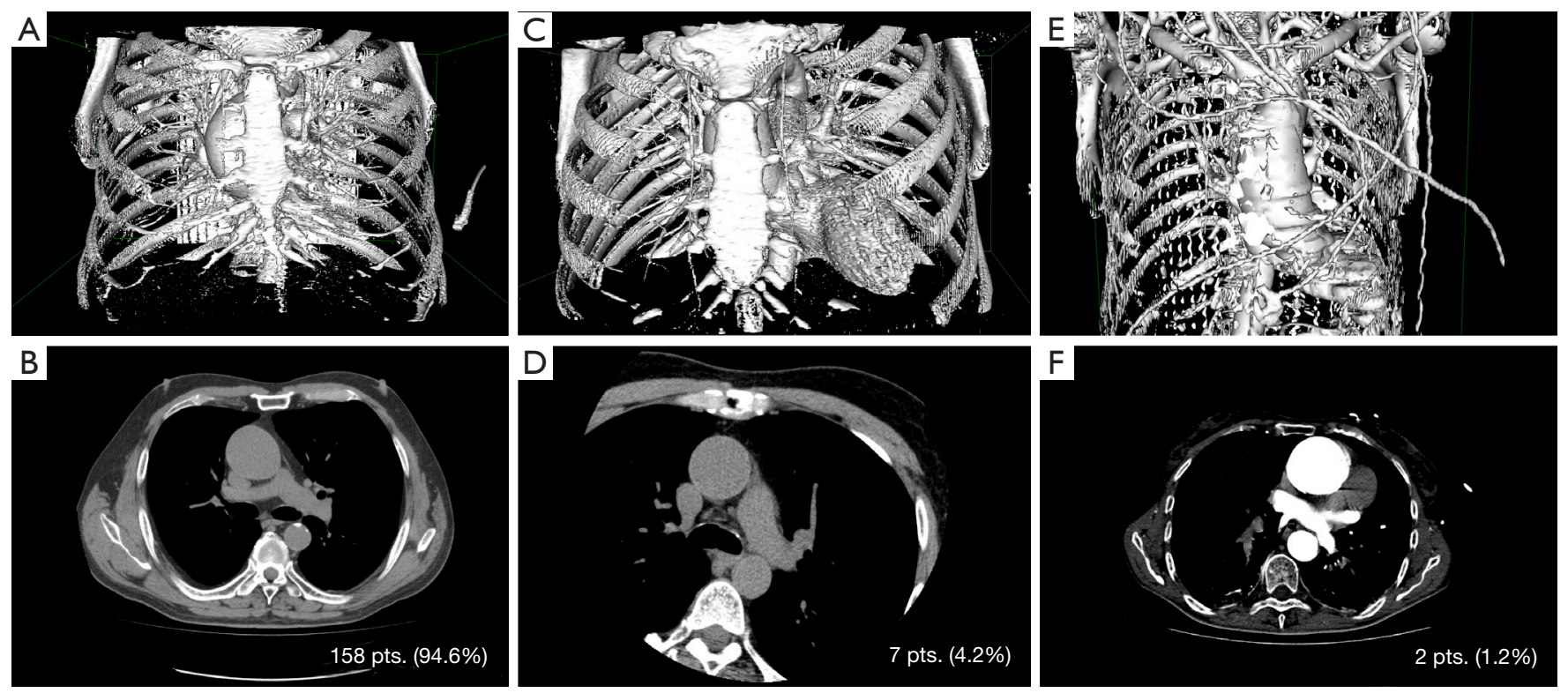

Figure 1 Preoperative CT imaging. Diverse retrosternal aorta positions (A,B: left sided; C,D: central; and E,F: right-sided) with corresponding percentage distribution across study population.

Bioglue was universally used to buttress the coronary button anastomoses during root procedures.

Ventricular (or atrial and ventricular) temporary pacing wires were placed. Reverse Trendelenburg manoeuvre and active LV filling were used to facilitate de-airing; aorta was then declamped and the patient weaned from CPB. Intraoperative TEE was than performed to assess the correct valve function and in particular signs of insufficiency in all patients. Cannulas were removed and protamine sulphate administration at 1:1 ratio to heparin unless activated clotting time was $>140 \mathrm{~s}$ which required additional doses. The above as well as transfusions of blood products while in operating room was left at the discretion of anaesthetist. Single chest drain tube was placed in the anterior mediastinum from subxiphoid access following venous cannula removal. Pericardium was closed with interrupted sutures in the upper portion. Sternum was brought together with steel wires (Figure $5 A, B$ ); choice between topical vancomycin paste application to the sternal edges (8) or gentamycin collagen sponge (9) placement between sternal halves was left to the surgeon's preference. The video footage covering surgical details is available elsewhere (10).

\section{Definitions and follow-up}

Acute kidney injury AKI was defined according to Kidney
Disease Improving Global Outcomes (KDIGO) criteria (11). KDIGO criteria define AKI as a $0.3 \mathrm{mg} / \mathrm{dL}(\geq 26.5 \mathrm{~mol} / \mathrm{L})$ $\mathrm{sCr}$ increase from baseline within 48 hours of surgery, a $50 \% \mathrm{sCr}$ increase from baseline within 7 days of surgery, or a decrease in urine output below $0.5 \mathrm{~mL} / \mathrm{kg} /$ hour for 6 hours. Residual aortic regurgitation was graded based on pressure half-time and classified in-between 'none', 'trace', 'mild' and ' $\geq$ moderate'. Follow-up visits were scheduled at 6,12 and 24 months. Longer follow-ups were collected telephonically. Survival data were obtained from KROK registry (12).

\section{Statistical analysis}

STATA MP v13.0 software (StataCorp, College Station, TX) was used for all computations. Normally distributed continuous variables were expressed as mean \pm standard deviation (SD) and as median and interquartile range (IQR). Nonparametric and parametric data were evaluated using either the Spearman rank-test or the Pearson test. The Kaplan-Meier curves were used for presentation of an overall survival and compared using log-rank test where applicable. A Cox regression adjustment for respective hazard ratios was than fitted taking into account duration of ECC and x-clamp. Proportional-hazards assumption test based on Schoenfeld residuals (phtest) was than applied. A 

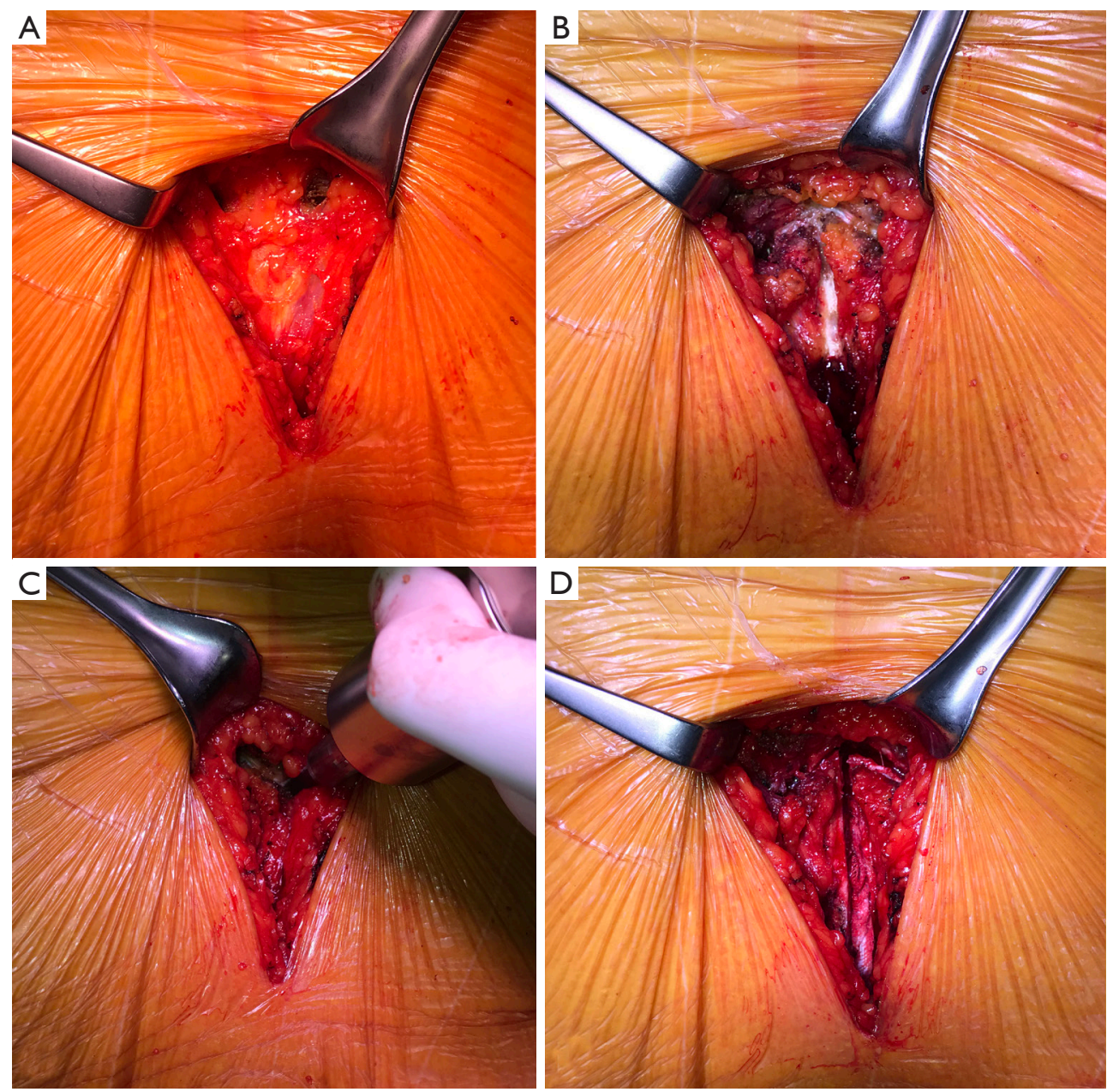

Figure 2 Surgical access to minimally invasive aortic surgery: skin incision (A); V-shaped" sternal incision (B); aorta exposure (C); cannulation for cardiopulmonary bypass (D).

prespecified subanalysis of patients undergoing minimally invasive aortic surgery with and without concomitant AVR was performed as well. A two-tailed P value of less than 0.05 was considered statistically significant for all statistical tests employed.

\section{Results}

Between 2011 and 2018, 167 selected low- and intermediate risk patients (mean age: $64.1 \pm 11.3 ; 70 \%$ men; EuroSCORE II $2.58 \pm 3.26$ ) underwent minimally invasive aortic surgery in our institution (10).

\section{Aortic position evaluation}

Each patient underwent preoperative CT which revealed positioning of the ascending aorta to the right of the sternum in $158(94.6 \%)$ (Figure 1A,B), central position of the aorta in $7(4.2 \%)$ (Figure 1C,D) and to the left in 2 patients (1.2\%) (Figure 1E,F).

\section{Surgery}

Subjects were divided into supracoronary aortic replacements (SCAR) [82 pts (49\%)], into SCAR + AVR [44 pts (26\%)] and minimally invasive root reimplantation/ replacement/remodelling (root RRR) procedures with 41 pts $(25 \%)$. Detailed baseline characteristics are listed in Table 1. There were no marked differences between three groups regarding baseline characteristics, comorbidities and history of other interventions, yet there were significantly more patients with EF $>50 \%$ in the SCAR subset. Similarly, 

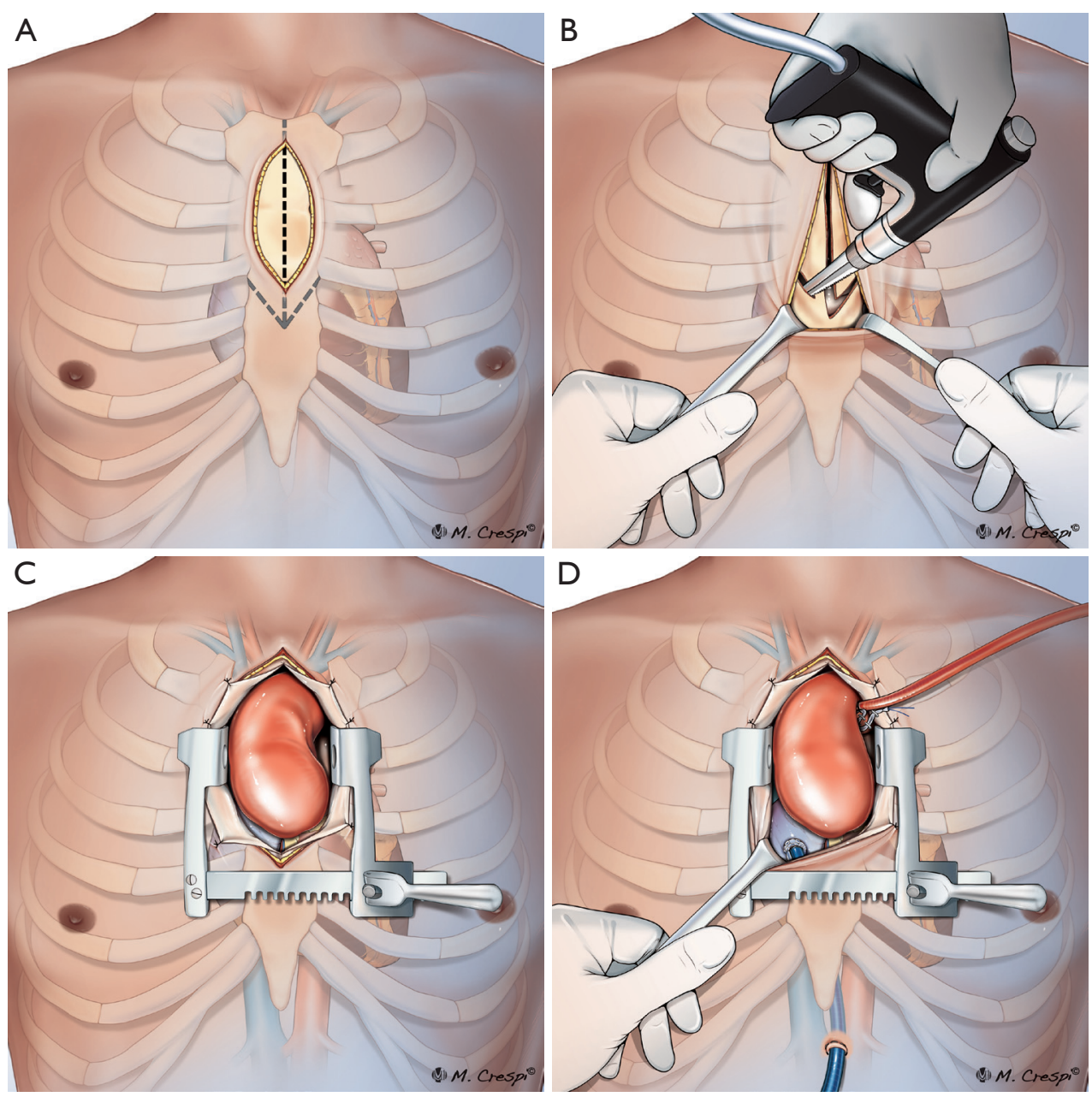

Figure 3 Step by step surgical technique: identification of 4th intercostal spaces (A); "arrow" shaped incision lines (B); a side-cut from intercostal space to sternal midline (C); "V-shaped" sternal incision (D).

the extent of procedure complexity did not differ across time frames imposed in the current study $(\mathrm{P}=0.42)$. Patients were further divided into AVR and non-AVR procedures; analysis of baseline characteristics according to AVR involvement are outlined as Table S1.

Table 2 lists procedural characteristics; there were 12 (7\%) bicuspid aortic valves; aortic valve insufficiency was diagnosed more frequently than stenosis (28\% vs. $17 \%)$; average diameter of the aortic aneurysm was $6.00 \pm 0.46 \mathrm{~cm}$ as measured with preoperative echocardiography. In the group of aortic surgery without AVR, SCAR was performed in $82(49 \%)$ cases and David/Yacoub procedures in 16 (10\%) (10) (Table S2). Subcommissural annuloplasty was performed in 7 patients: five in the group of SCAR and 2 in minimally invasive root repair (Table 2). Bentall-de Bono procedures accounted for $61 \%$ in this group. There were no differences regarding the valve type: bioprostheses were implanted in $36 \mathrm{pts}$ and mechanical valves in 33 pts (22\% vs. $20 \%$ respectively). There was one 'planned' conversion to full sternotomy in 42 y.o. male with ascending aorta aneurysm of $6.9 \mathrm{~cm}$. Extracorporeal circulation-as well as aortic $x$-clamp-times were statistically longer in SCAR+AVR (on average by 44 and 33 minutes respectively) and in minimally invasive root RRR group (on average by 92 and 71 minutes respectively); yet there were no marked differences with respect to inotropic support, need for mechanical support, transfusions and ICU length of stay.

\section{Early results}

There was one in-hospital death $(1 \%)$ in patient who underwent supracoronary aortic replacement that occurred 

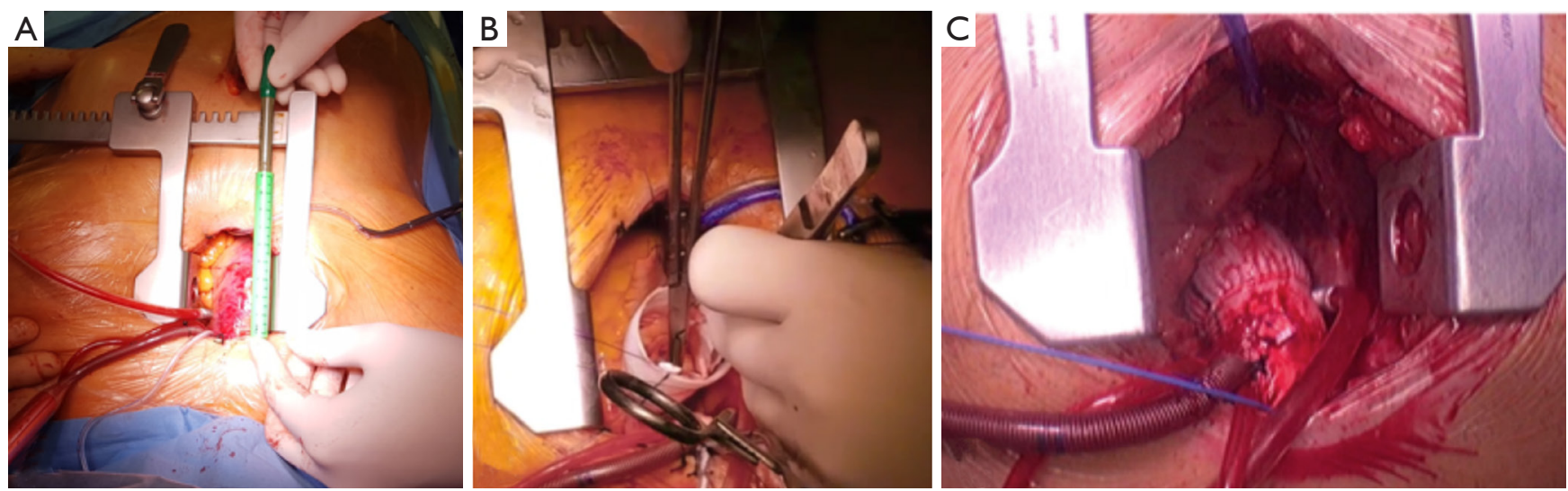

Figure 4 Direct aortic cannulation (A); David procedure (B); final result, prosthesis in place (C) courtesy of EACTS: MITACS 20-22 June Warsaw, Poland Course Report.
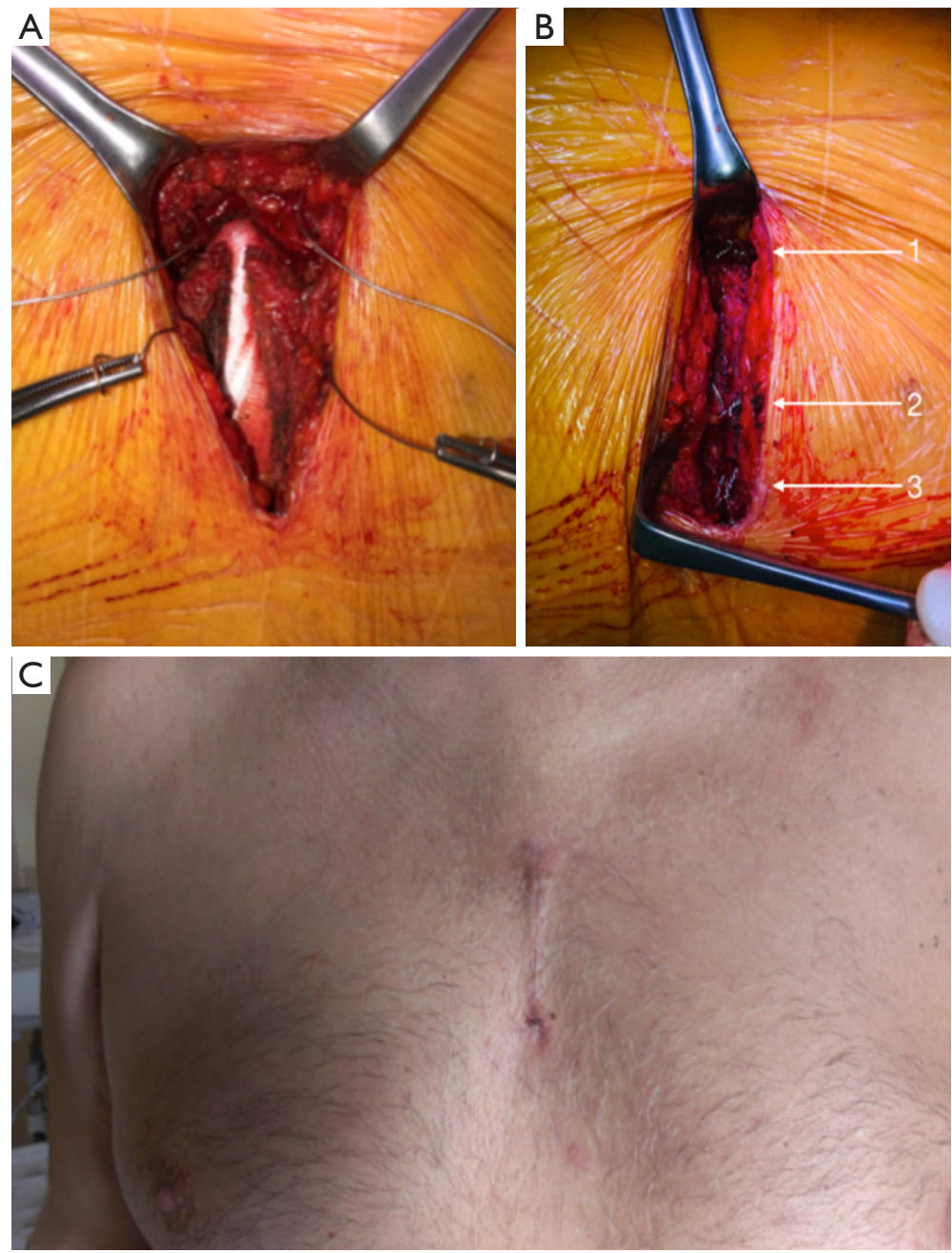

Figure 5 Closing of the sternum with 3 steel wires $(A, B)$ arrows point to the wires in place; one-month cosmetic outcome (C). 
at postop day $40^{\text {th }}$ and was attributed to multiorgan failure following massive pulmonary embolism and ECMO therapy; other $2 \mathrm{ECMO}$ cases were patients in supracoronary aortic replacement + AVR group; both were weaned successfully and discharged uneventfully. Five neurologic complications were noted (4 TIAs and 1 stroke); AKI was present in $8(5 \%)$ of the treated patients; none of them required permanent dialysis. Remaining complications are detailed in Table 3; there were no statistically significant subgroup differences. There were no statistical differences in the rates of complications between minimally invasive aortic surgery with- and without concomitant AVR either (Table S3). No case of "more-than-mild" aortic regurgitation was observed intraoperatively and in the discharge echocardiography.

\section{Mid-term results}

One-month cosmetic results were documented (Figure 5C). Two patients presented "more-than-mild" (grade $>1$ ) aortic regurgitation during 6-month follow-up echocardiography; and were both in the group of supracoronary aortic replacement without concomitant AVR. Echocardiographic parameters of patients undergoing minimally invasive valve sparing aortic root reimplantation/remodelling (David/ Yacoub) procedures are detailed in Table 4. One patient was reoperated through median sternotomy after 24 months following acute thrombosis of aortic valve bioprosthesis. Late survival was estimated at 95\% (Figure 6A). There were no differences in survival estimates according to the type of procedure performed as well: HR, 0.81; 95\% CI: 0.36-1.81; $\mathrm{P}=0.61$ (Figure $6 \mathrm{~B}$ ) for comparison supracoronary aortic replacement vs. supracoronary aortic replacement + AVR vs. root RRR [proportional-hazards assumption phtest (Prob > $\left.\chi^{2}=0.058\right)$ ]. Similarly, no differences for comparison aortic surgery with- $v s$. without AVR were seen: HR, 0.96; $95 \%$ CI: 0.26-3.59; $\mathrm{P}=0.95$ (Figure S1).

\section{Discussion}

An essential aim in cardiovascular and thoracic surgery is to minimize surgical trauma to gain faster recovery (13). Shresta et al. in a series of 26 patients demonstrated that minimally invasive valve sparing aortic root reimplantation can be safely performed in selected subjects. The results were comparable to those operated via a full sternotomy earlier in the experience. Authors emphasized that key to success is a 'step by step' technique of moving from minimally invasive AVR to more demanding aortic root procedures (6). Mikus et al. reported on 53 patients undergoing ascending aorta and aortic valve replacement using Bentall-De Bono procedure. Median cardiopulmonary bypass time and median cross-clamp time were respectively 84 (IQR, 75-103) minutes and 73 (IQR, 64-89) minutes in this series. Median intensive care unit and hospital stay were 1.9 and 8 days, respectively (4). In another study by Deschka et al. authors successfully expanded the surgery beyond the aortic root: with 50 consecutive patients undergoing procedures of the ascending aorta and the aortic arch using partial upper sternotomy. Thirty-six patients underwent replacement or tightening of the ascending aorta, 11 patients received additional replacement of the proximal arch and in 3 cases, a complete replacement of the aortic arch was performed with $100 \%$ survival (14). Our experience reflects those of other centres with minimally invasive aortic surgery being a natural evolution of miniAVR; with single steps gradually added to standard miniAVR procedure; indeed, every single isolated aortic aneurysm is now operated in minimally invasive fashion. Much of the remaining literature shows the feasibility and outcomes of minimally invasive techniques for complex aortic pathology involving some type of partial sternotomy, be that $\mathrm{T}$-incision (15) right side partial sternotomy (16) parasternal incision (17) L incision (18) etc. Unlike others, LaPietra et al. discusses novel technique of performing minimally invasive complex aortic surgery with AVR via a right anterior thoracotomy, without any sternal invasion on 20 consecutive patients with promising results (19).

Indications for surgery, primarily restricted only to selected elective patients and single procedures is now being extended to more complex surgeries including, in the same time, aortic root, ascending aorta and aortic valve. Best reflecting previous findings, our report demonstrated that upper "V" shaped ministernotomy guarantees surgical exposure of the aortic root optimal to perform all types of ascending aorta and aortic root procedures using totally central cannulation. Central cannulation paradoxically, allows for better exposure of the aortic root, since the tip or right atrium appendage is pulled downwards by the venous cannula traction.

Present report demonstrated feasibility of ministernotomy approach for aortic procedures with good early outcomes no matter the extent of the repair from simple supracoronary replacements to complex root procedures; there was one in-hospital death that was however not related to the surgery itself, rather it was linked to pulmonary embolism, ECMO therapy and following multiorgan failure; one stroke occurred that was 
Table 1 Pre-operative characteristics

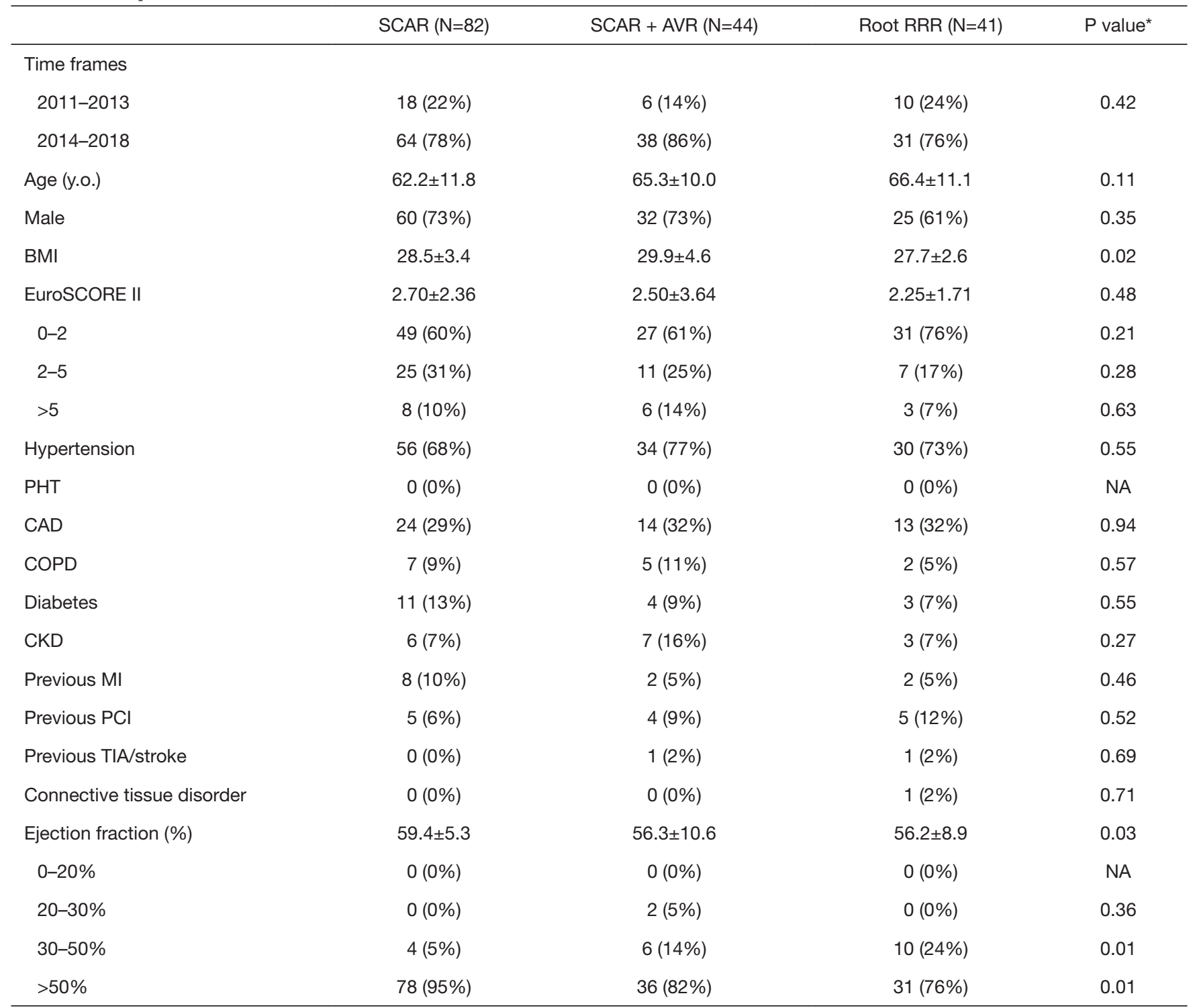

${ }^{*} \mathrm{P}$ value for between groups difference. SCAR, supracoronary aortic replacement; AVR, aortic valve replacement; RRR, reimplantation/ replacement/remodelling; BMI, body mass index; $\mathrm{PHT}$, pulmonary hypertension; CAD, coronary artery disease; COPD, chronic obstructive pulmonary disease; CKD, chronic kidney disease; MI, myocardial infarction; PCI, percutaneous coronary intervention; TIA, transient ischemic attack.

managed conservatively and otherwise healthy patient was discharged to neurological rehabilitation unit. There were two wound healing issues; one superficial sternal wound infection (SWI) and one deep SWI that required surgical debridement and vacuum assisted closure therapy. Given the complexity of the minimally invasive root surgeries carried out in the series we were not able to demonstrate that the longer duration of CPB and X-clamp in these patients have anyhow influenced the number of transfusions, kidney function and hard clinical endpoints as compared to simple supracoronary replacements.

Our study represents one of largest single centre's series carried out in the setting of minimally invasive root RRR since most technically challenging with the mini-sternotomy access, it seems that preoperative imaging plays crucial role in identification and selection of patients for this approach. Both CT and echocardiography are essential to examine dimensions and morphological parameters in ascending 
Table 2 Intra-operative characteristics

\begin{tabular}{|c|c|c|c|c|}
\hline & $\operatorname{SCAR}(\mathrm{N}=82)$ & $S C A R+A V R(N=44)$ & Root RRR (N=41) & $P$ value \\
\hline AV stenosis & $0(0 \%)$ & $27(61 \%)$ & $2(5 \%)$ & $<0.001$ \\
\hline AV insufficiency & $5(6 \%)$ & $19(43 \%)$ & $23(56 \%)$ & $<0.001$ \\
\hline Bicuspid valve & $1(1 \%)$ & $5(11 \%)$ & $6(15 \%)$ & 0.056 \\
\hline Ascending aorta $(\mathrm{cm})$ & $6.17 \pm 0.44$ & $5.67 \pm 0.46$ & $6.02 \pm 0.29$ & $<0.001$ \\
\hline \multicolumn{5}{|l|}{ Aortic root surgery } \\
\hline David/Yacoub & - & - & $16(39 \%)$ & NA \\
\hline Bentall-de Bono & - & - & $25(61 \%)$ & NA \\
\hline \multicolumn{5}{|l|}{$\mathrm{SCAR}+\mathrm{AVR}$} \\
\hline Bioprosthesis & - & $18(41 \%)$ & - & NA \\
\hline Mechanical valve & - & $26(59 \%)$ & - & NA \\
\hline Subcommissural annuloplasty & $5(6 \%)$ & $0(0 \%)$ & $2(5 \%)$ & 0.50 \\
\hline Hemi-arch replacement & $0(0 \%)$ & $0(0 \%)$ & $1(2 \%)$ & 0.71 \\
\hline $\mathrm{ECC}(\mathrm{min})$ & $117.9 \pm 23.0$ & $161.4 \pm 26.5$ & $209.8 \pm 37.2$ & $<0.001$ \\
\hline X-clamp (min) & $75.7 \pm 15.3$ & $108.3 \pm 17.8$ & $146.9 \pm 35.9$ & $<0.001$ \\
\hline Postoperative drainage $(\mathrm{mL})$ & $337.6 \pm 191.4$ & $387.8 \pm 221.3$ & $440.8 \pm 218.8$ & 0.031 \\
\hline FFP $(U)$ & $1.44 \pm 1.58$ & $1.92 \pm 1.61$ & $2.05 \pm 1.49$ & 0.072 \\
\hline PLT (U) & $0.19 \pm 0.39$ & $0.60 \pm 1.34$ & $0.27 \pm 0.51$ & 0.11 \\
\hline Conversion & $0(0 \%)$ & $0(0 \%)$ & $1(2 \%)$ & 0.71 \\
\hline
\end{tabular}

${ }^{\star} \mathrm{P}$ value for between groups difference. SCAR, supracoronary aortic replacement; AVR, aortic valve replacement; RRR, reimplantation/ replacement/remodelling; ECC, extracorporeal circulation; ICU, intensive care unit; RBC, red blood cells; FFP, fresh frozen plasma; PLT, platelets. Remaining abbreviations as in Table 1.

aorta pathologies; not only it helped to choose "J" or "V" incision according to the position of the aorta (J-shaped may be preferred in selected patients; also it may be associated with less bleeding due to reduced exposure of bone marrow) but foremost it allows for identifying presence of calcific plaques in the area of aortic cannulation, clamp and distal anastomosis that may not be palpable initially. In addition, detailed CT imaging will allow to select patients for even less invasive aortic procedures in the future such as those performed with right anterolateral thoracotomy (20).

Single case of hemi-arch procedure was included in the series; with highly selected patients and adequately low positioned aortic arch on preoperative imaging, we believe that mini-sternotomy may pose a valid approach for aortic 
Table 3 Complications

\begin{tabular}{|c|c|c|c|}
\hline & $\operatorname{SCAR}(\mathrm{N}=82)$ & SCAR + AVR $(\mathrm{N}=44)$ & Root RRR $(\mathrm{N}=41)$ \\
\hline Cardiac tamponade and/or re-thoracotomy for bleeding* & $7(9 \%)$ & $3(7 \%)$ & $2(5 \%)$ \\
\hline Periprocedural MI & $1(1 \%)$ & $1(2 \%)$ & $0(0 \%)$ \\
\hline Respiratory failure & $2(2 \%)$ & $1(2 \%)$ & $1(2 \%)$ \\
\hline Neurologic complications & $2(2 \%)$ & $2(5 \%)$ & $1(2 \%)$ \\
\hline Pulmonary embolism & $1(1 \%)$ & $0(0 \%)$ & $0(0 \%)$ \\
\hline Multiorgan failure & $2(2 \%)$ & $1(2 \%)$ & $0(0 \%)$ \\
\hline Gastrointestinal complications & $1(1 \%)$ & $1(2 \%)$ & $1(2 \%)$ \\
\hline ECMO & $1(1 \%)$ & $2(5 \%)$ & $0(0 \%)$ \\
\hline VAD & $0(0 \%)$ & $0(0 \%)$ & $0(0 \%)$ \\
\hline
\end{tabular}

MI, myocardial infarction; ICU, intensive care unit; ECMO, extracorporeal membrane oxygenation; VAD, ventricle assist device. Remaining abbreviations as in Table 1. *inclusive of cases undergoing packing removal and secondary sternal closure.

Table 4 TTE follow-up in patients undergoing minimally invasive aortic root reimplantation/remodelling surgery

\begin{tabular}{lc}
\hline & Outcome \\
\hline LVEF $(\%)$ & $56 \pm 7$ \\
Aortic mean gradient $(\mathrm{mmHg})$ & $7 \pm 5$ \\
LVEDD $(\mathrm{mm})$ & $56 \pm 7$ \\
Sinuses of Valsalva $(\mathrm{mm})$ & $30 \pm 4$ \\
Ascending aorta $(\mathrm{mm})$ & $28 \pm 4$ \\
Aortic regurgitation & \\
None & 12 pts. \\
AR mild & 4 pts. \\
AR moderate & 0 pts. \\
AR severe & 0 pts. \\
\hline
\end{tabular}

TTE, transthoracic echocardiography; LVEF, left ventricular ejection fraction; AR, aortic regurgitation; LVEDD, left ventricular end diastolic diameter.

arch pathologies as well, with or without deep hypothermic circulatory arrest (DHCA) according to surgeon's experience and arch pathology. Even with $6 \mathrm{~cm}$ incision it is possible to access neck vessels in the upper portion of the chest allowing easy exposure of the aortic arch; on the other hand, we would argue against this approach if selective antegrade cerebral perfusion is planned since incision that little may not be enough for easy manipulation of the aortic arch in the time of replacement. Svensson et al. reports on 18 patients who had aortic arch repaired through ministernotomy (21) but the authors used combination of retrograde and antegrade cerebral perfusion and DHCA.

The current study is one of the few to report mid-term outcomes for patients who underwent aortic root, and/ or ascending aorta replacement with or without concomitant AVR via ministernotomy approach. Tabata et al. performed a retrospective review of 128 patients who had ascending aortic, arch, and root surgery via an upper ministernotomy. They were able to follow their patients for 5 years. They concluded that not only was this approach feasible for complex aortic pathology, but they had an excellent 5 -year survival of $97.2 \%$ (22). Exceptional results up to 10 years were also reported from Cleveland Clinic experience (23). Within investigated follow-up (mean 3.1, max 7.7) we could demonstrate a similar survival estimated at $95 \%$ without differences between procedures involving AVR or not: HR, 0.96; 95\% CI: 0.26-3.59; $\mathrm{P}=0.95$; remarkably only one patient required reintervention within these time frames; 24 months postoperatively he developed acute valve thrombosis; this patient was operated on urgently and via full sternotomy. 

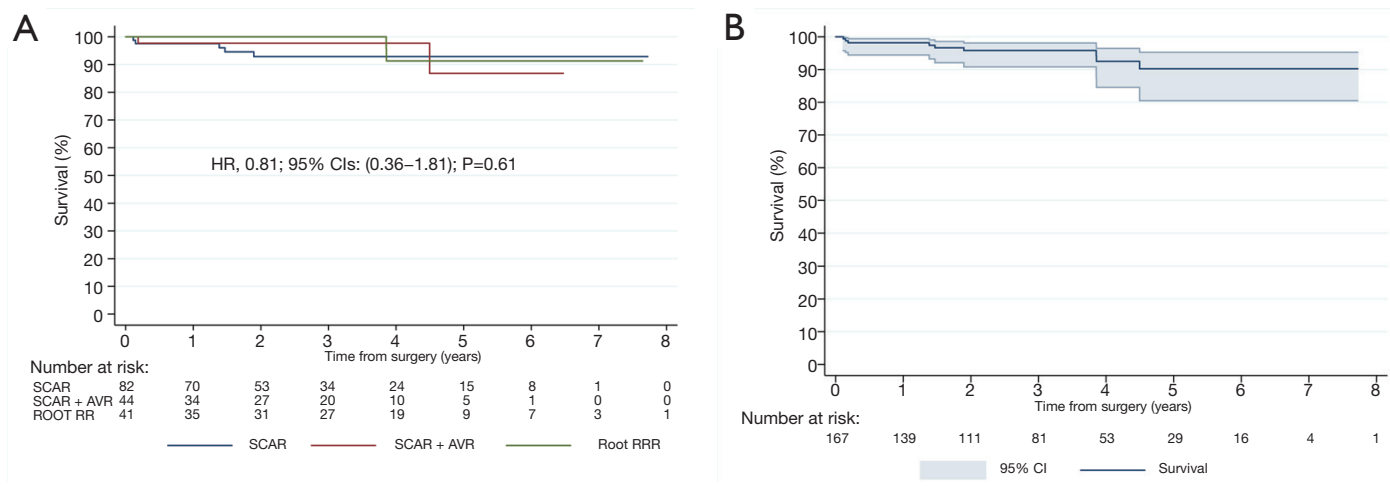

Figure 6 Kaplan-Meier curve for the analysis of overall survival in patients undergoing minimally invasive aortic surgery (A) and stratified by aortic surgery technique (B). SCAR, supracoronary aortic replacement; AVR, aortic valve replacement; RRR, reimplantation/replacement/ remodelling HR, hazard ratio; CI, confidence interval.

\section{Limitations}

Certain limitations inherent in a single-center, retrospective study design need to be acknowledged. Firstly, there is a lack of control group involving full sternotomy approach; yet for the past 8 years, full sternotomy was reserved for complex multi-valve, additional CABG, dissections both acute and chronic and re-do surgery cases in our institution; we believe use of such control group with much higher risk patients would promote artificiality and selection bias in this perspective. We have observed operative times similar or shorter on average to ones observed in the literature; these are however subjective to learning curve as we obtained higher values early in the experience (2011-2013).

\section{Conclusions}

Minimally invasive aortic surgery performed through "V" shaped partial upper sternotomy is feasible and safe in selected patients regardless of the extent of repair, from supracoronary aorta replacements to complex root surgery.

\section{Acknowledgments}

Funding: None.

\section{Footnote}

Reporting Checklist: The authors have completed the STROBE reporting checklist. Available at http://dx.doi. org/10.21037/jtd-20-2165
Data Sharing Statement: Available at http://dx.doi. org/10.21037/jtd-20-2165

Conflicts of Interest: All authors have completed the ICMJE uniform disclosure form (available at http://dx.doi. org/10.21037/jtd-20-2165). Dr. Kowalewski serves as an unpaid editorial board member of Journal of Thoracic Disease from Sep 2020 to Aug 2022. The other authors have no conflicts of interest to declare.

Ethical Statement: The authors are accountable for all aspects of the work in ensuring that questions related to the accuracy or integrity of any part of the work are appropriately investigated and resolved. This study conformed to the provisions of the Declaration of Helsinki (as revised in 2013) and was approved by the local ethics committee (CSK MSWiA/KE/215/2018), and each patient signed an informed consent for treatment and use of personal data.

Open Access Statement: This is an Open Access article distributed in accordance with the Creative Commons Attribution-NonCommercial-NoDerivs 4.0 International License (CC BY-NC-ND 4.0), which permits the noncommercial replication and distribution of the article with the strict proviso that no changes or edits are made and the original work is properly cited (including links to both the formal publication through the relevant DOI and the license). See: https://creativecommons.org/licenses/by-nc-nd/4.0/.

\section{References}

1. Chang C, Raza S, Altarabsheh SE, et al. Minimally 
invasive approaches to surgical aortic valve replacement: A meta-analysis. Ann Thorac Surg 2018;106:1881-9.

2. Phan K, Xie A, Tsai YC, et al. Ministernotomy or minithoracotomy for minimally invasive aortic valve replacement: A bayesian network meta-analysis. Ann Cardiothorac Surg 2015;4:3-14.

3. Abjigitova D, Panagopoulos G, Orlov O, et al. Current trends in aortic root surgery: The mini-bentall approach. Innovations (Phila) 2018;13:91-6.

4. Mikus E, Micari A, Calvi S, et al. Mini-bentall: An interesting approach for selected patients. Innovations (Phila) 2017;12:41-5.

5. Monsefi N, Risteski P, Miskovic A, et al. Midterm results of a minimally invasive approach in david procedure. Thorac Cardiovasc Surg 2018;66:301-6.

6. Shrestha M, Krueger H, Umminger J, et al. Minimally invasive valve sparing aortic root replacement (david procedure) is safe. Ann Cardiothorac Surg. 2015;4:148-53.

7. Nashef SA, Roques F, Sharples LD, et al. EuroSCORE II. Eur J Cardiothorac Surg 2012;41:734-44; discussion 744-35.

8. Kowalewski M, Raffa GM, Szwed KA, et al. Meta-analysis to assess the effectiveness of topically used vancomycin in reducing sternal wound infections after cardiac surgery. J Thorac Cardiovasc Surg. 2017;154:1320-3.e1323.

9. Kowalewski M, Pawliszak W, Zaborowska K, et al. Gentamicin-collagen sponge reduces the risk of sternal wound infections after heart surgery: Meta-analysis. J Thorac Cardiovasc Surg 2015;149:1631-40.e1631-6.

10. Staromlynski J, Kowalewski M, Smoczynski R, et al. Minimally invasive approach to ascending aorta- and aortic root surgery. Interact Cardio Vasc Thorac Surg 2020. [Epub ahead of print].

11. Petäjä L, Vaara S, Liuhanen S, et al. Acute kidney injury after cardiac surgery by complete kdigo criteria predicts increased mortality. J Cardiothorac Vasc Anesth 2017;31:827-36.

12. Suwalski P, Kowalewski M, Jasinski M, et al. Survival after surgical ablation for atrial fibrillation in mitral valve surgery: Analysis from the polish national registry of cardiac surgery procedures (KROK). J Thorac Cardiovasc Surg 2019;157:1007-18.e4.

Cite this article as: Staromłyński J, Kowalewski M, Sarnowski W, Smoczyński R, Witkowska A, Bartczak M, Drobiński D, Wierzba W, Suwalski P. Midterm results of less invasive approach to ascending aorta and aortic root surgery. J Thorac Dis 2020;12(11):6446-6457. doi: 10.21037/jtd-20-2165
13. Phan K, Xie A, Di Eusanio M, et al. A meta-analysis of minimally invasive versus conventional sternotomy for aortic valve replacement. Ann Thorac Surg 2014;98:1499-511.

14. Deschka H, Erler S, Machner M, et al. Surgery of the ascending aorta, root remodelling and aortic arch surgery with circulatory arrest through partial upper sternotomy: Results of 50 consecutive cases. Eur J Cardiothorac Surg 2013;43:580-4.

15. Perrotta S, Lentini S. Ministernotomy approach for surgery of the aortic root and ascending aorta. Interact Cardiovasc Thorac Surg 2009;9:849-58.

16. Kasegawa H, Shimokawa T, Matsushita Y, et al. Rightsided partial sternotomy for minimally invasive valve operation: "Open door method". Ann Thorac Surg 1998;65:569-70.

17. Cohn LH, Adams DH, Couper GS, et al. Minimally invasive cardiac valve surgery improves patient satisfaction while reducing costs of cardiac valve replacement and repair. Ann Surg 1997;226:421-6; discussion 427-8.

18. Watanabe G, Takemura H, Tomita S, et al. Multiple minimally invasive direct cabg for the complete revascularization: The figure 1 approach. Thorac Cardiovasc Surg 2003;51:28-32.

19. LaPietra A, Santana O, Pineda AM, et al. Outcomes of aortic valve and concomitant ascending aorta replacement performed via a minimally invasive right thoracotomy approach. Innovations (Phila) 2014;9:339-42; discussion 342.

20. Lamelas J, Chen PC, Loor G, et al. Successful Use of Sternal-Sparing Minimally Invasive Surgery for Proximal Ascending Aortic Pathology. Ann Thorac Surg 2018;106:742-8.

21. Svensson LG, Nadolny EM, Kimmel WA. Minimal access aortic surgery including re-operations. Eur J Cardiothorac Surg 2001;19:30-3.

22. Tabata M, Khalpey Z, Aranki SF, et al. Minimal access surgery of ascending and proximal arch of the aorta: A 9-year experience. Ann Thorac Surg 2007;84:67-72.

23. Johnston DR, Roselli EE. Minimally invasive aortic valve surgery: Cleveland Clinic experience. Ann Cardiothorac Surg 2015;4:140-7. 